\title{
Thermal-durability Evaluation of Inflatable Structure for a Deployable Aeroshell Using ICP Heater
}

\author{
By Kazushige Matsumaru, ${ }^{1)}$ Mayuko TAnAKA, ${ }^{2)}$ Osamu ImamurA, ${ }^{3)}$ and Kazuhiko YamadA ${ }^{4)}$ \\ ${ }^{1)}$ Department of Mechanical Engineering, Nihon University, Narashino, Japan \\ ${ }^{2}$ Department of Applied Mechanics, Waseda University, Tokyo, Japan \\ ${ }^{3}$ Department of Sustainable Engineering, Nihon University, Narashino, Japan \\ ${ }^{4}$ Institute of Space and Astronautical Science, JAXA, Sagamihara, Japan
}

(Received June 23rd, 2017)

\begin{abstract}
In recent years, a number of sample return mission and planetary exploration probes have been discussed and proposed. Our group has developed a new atmospheric re-entry vehicle with a membrane aeroshell to increase the variety of these missions. However, there are still several important technical problems to be addressed to apply the membrane aeroshell to an actual mission. One of them is evaluation of the thermal durability of the inflatable structure. The thermal durability of the inflatable structure was evaluated using a $10 \mathrm{~kW}$ class inductively coupled plasma (ICP) heater. This ICP heater can produce a plasma flow with a high enthalpy and relatively low heat flux of about $120 \mathrm{~kW} / \mathrm{m}^{2}$, which is a suitable condition for the heating test of the membrane aeroshell. The tests proved that the inflatable structure, made of polyimide film, silicon rubber adhesive, ZYLON textile, and alumina felt, maintains the gas tight in the plasma flow with a heat flux of $120 \mathrm{~kW} / \mathrm{m}^{2}$ in $300 \mathrm{~s}$. This layering structure is proposed as a potential candidate for use in actual flight vehicles.
\end{abstract}

Key Words: Aerodynamic Heating, Atmospheric Re-entry, Membrane Aeroshell, ICP Heater

\section{Introduction}

In recent years, a number of sample return missions and planetary exploration probes have been discussed and proposed. The atmospheric entry technology is indispensable to realize these missions. The most important technical issue concerning atmospheric entry is aerodynamic heating. The existing atmospheric entry vehicles are the rigid capsule type, like the "Hayabusa" sample return capsule (SRC), and the wing type, like space shuttles. These vehicles have to be tolerant against aerodynamic heating using thermal protection tiles and ablator materials. Our group has been developing new atmospheric re-entry vehicles with a deployable membrane aeroshell. Figure 1 shows a conceptual image in which the membrane aeroshell is applied to a re-entry / recovery system from a low earth orbit (LEO). This membrane aeroshell consists of a thin membrane flare and the inflatable ring. This aeroshell can be deployed by injecting pressurized gas into the inflatable ring, and the deployed aeroshell is maintained by the inner pressure of this ring. Atmospheric entry vehicles with a large area and light-weight membrane aeroshell have a low ballistic coefficient. Thanks to their low ballistic coefficient, such atmospheric entry vehicles can efficiently generate an aerodynamic force during the atmospheric entry, and decelerate at high altitude where the atmospheric density is low. ${ }^{1)}$ Therefore, the maximum aerodynamic heating can be reduced dramatically. This is a unique concept, which is different from conventional atmospheric entry vehicles like the space shuttle and the Hayabusa SRC.

Various ground tests were conducted to apply this technology to an actual mission. For example, a structural strength test using a large low-speed wind tunnel, and transonic, supersonic, and hypersonic wind tunnel tests using a scaled model to investigate the aerodynamic characteristics in all ranges of the Mach number. Furthermore, our group conducted a reentry demonstration of the membrane aeroshell from an altitude of $150 \mathrm{~km}$ using the S-310 sounding rocket, ${ }^{2)}$ and aeroshell deployment demonstration in LEO using a nanosatellite re-entry satellite with the gossamer aeroshell and GPS/iridium (EGG). ${ }^{3)}$ However, several important technical problems have to be solved in order to apply the membrane aeroshell to actual missions. One of them is the evaluation of the inflatable structure thermal-durability. In this paper, heating tests against aerodynamic heating using the simple inflatable structure were carried out with a $10 \mathrm{~kW}$ ICP heater. The thermal durability of the inflatable structure developed for the actual reentry vehicle was investigated experimentally. In addition, the influence of the layering structure on thermal durability was investigated.

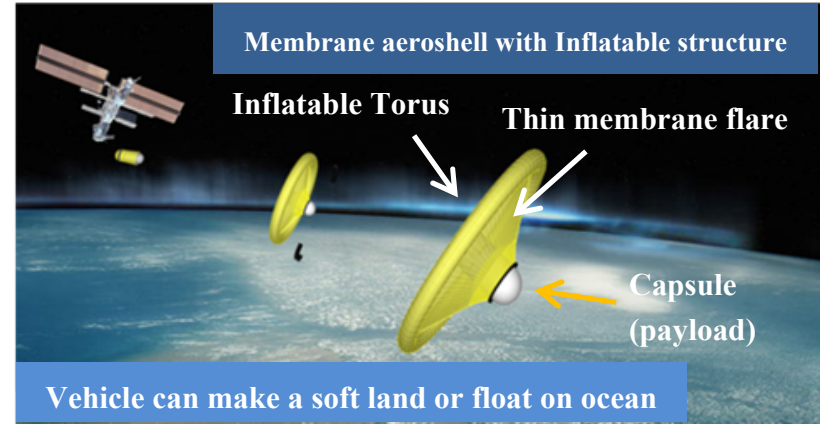

Fig. 1. Conceptual image of a re-entry vehicle using the membrane aeroshell. 


\section{Aerodynamic Heating Environment and Layering Structure of Inflatable Aeroshell}

First, the aerodynamic heating condition of the low ballistic coefficient reentry vehicle with the membrane aeroshell is estimated by a simple numerical reentry trajectory simulation. In this simulation, it is assumed that the $15 \mathrm{~kg}$ mass atmospheric entry vehicle with a $2.5 \mathrm{~m}$ diameter membrane aeroshell re-enters into the Earth's atmosphere from a LEO. Table 1 lists the reentry conditions and specifications of the reentry vehicle with the membrane aeroshell assumed for this simulation. This vehicle re-enters the atmosphere with a deceleration of $90 \mathrm{~m} / \mathrm{s}$ from a circular orbit with an altitude of $400 \mathrm{~km}$. In this simulation, only the gravity and aerodynamic drag forces are considered as external forces acting on the reentry vehicle. The drag coefficient is assumed to be 1.5 in the hypersonic regime. The heat flux at stagnation was estimated by the Tauber's empirical formula. ${ }^{4}$ Figure 2 shows the time history of the stagnation heat flux and the dynamic pressure during reentry. Then, the maximum heat flux at stagnation was estimated to be $140 \mathrm{~kW} / \mathrm{m}^{2}$, and the maximum dynamic pressure was estimated to be $0.16 \mathrm{kPa}^{5 \text { ) }}$

Table 1. Reentry conditions of membrane aeroshell.

\begin{tabular}{ll}
\hline Total mass & $15 \mathrm{~kg}$ \\
\hline Membrane aeroshell diameter & $2.5 \mathrm{~m}$ \\
\hline Curvature radius at stagnation & $0.4 \mathrm{~m}$ \\
\hline Drag coefficient & 1.5 \\
\hline Initial altitude & $400 \mathrm{~km}$ \\
\hline Initial speed & $7579 \mathrm{~m} / \mathrm{s}$ \\
\hline Initial path angle & $0^{\circ}$ \\
\hline
\end{tabular}

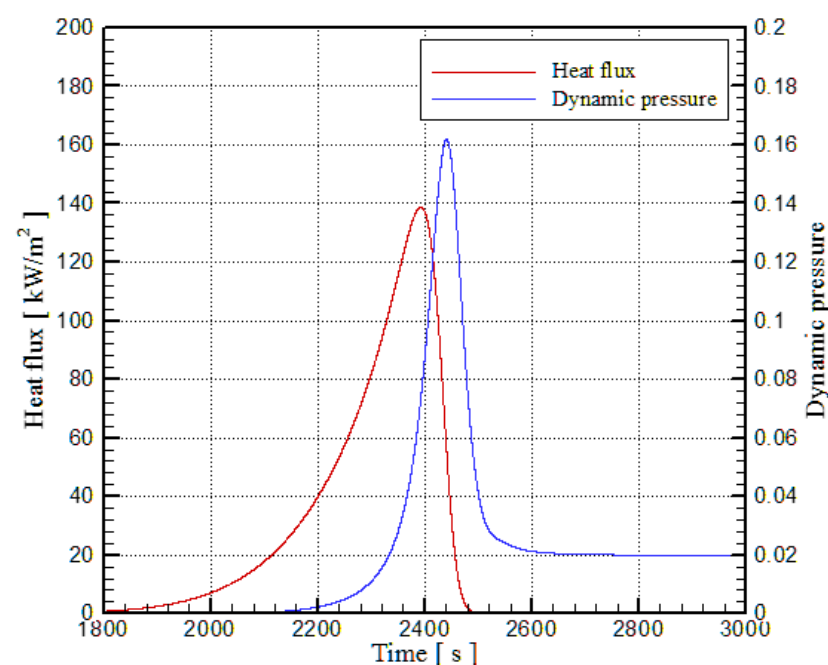

Fig. 2. Time history of heat flux and dynamic pressure in aerodynamic heating environment when vehicle with membrane aeroshell reenters from LEO.

The aerodynamic heating that the membrane aeroshell experiences during reentry is much lower than the aerodynamic heating for the conventional rigid capsules, which is about $1 \mathrm{MW} / \mathrm{m}^{2}$. The membrane aeroshell is required to endure this moderated aerodynamic heating environment. The inflatable torus is the weakest in thermal durability in the membrane aeroshell structure. The heat flux at the inflatable torus is lower than the stagnation point. It is estimated to be $110 \mathrm{~kW} / \mathrm{m}^{2}$ according to past research.

The layering structure of the envelope of the inflatable structure and materials are presented in Fig. 3 and Table 2, respectively. These materials are selected considering the usage for real reentry vehicles. The inflatable ring is a three-layered structure. The inner-layer is gas-tight layer made by a polyimide film (maximum allowable temperature: $550{ }^{\circ} \mathrm{C}$ ) which has a thickness of $12.5 \mu \mathrm{m}$. The polyimide film is bonded together to close the envelope using silicon rubber adhesive (maximum allowable temperature: $300{ }^{\circ} \mathrm{C}$ ). The middle-layer is the ZYLON filament textile (maximum allowable temperature: $650{ }^{\circ} \mathrm{C}$ ), which protects the inner-layer from mechanical damage. The outer-layer, which withstands the inner pressure, consists of two ZYLON filament textiles. This three-layered structure is called the basic structure. In addition, a thermal insulating layer made of alumina continuous felt and an alumina continuous fiber cloth are attached only on the heated surface of the inflatable structure to protect it from the aerodynamic heating. The surface of the thermal insulator made of alumina was painted in black to enhance the radiation cooling effect. Past research has proved that the surface color has a significant effect on the thermal condition of inflatable structures. ${ }^{6)}$ The heating tests were carried out using these inflatable structures.

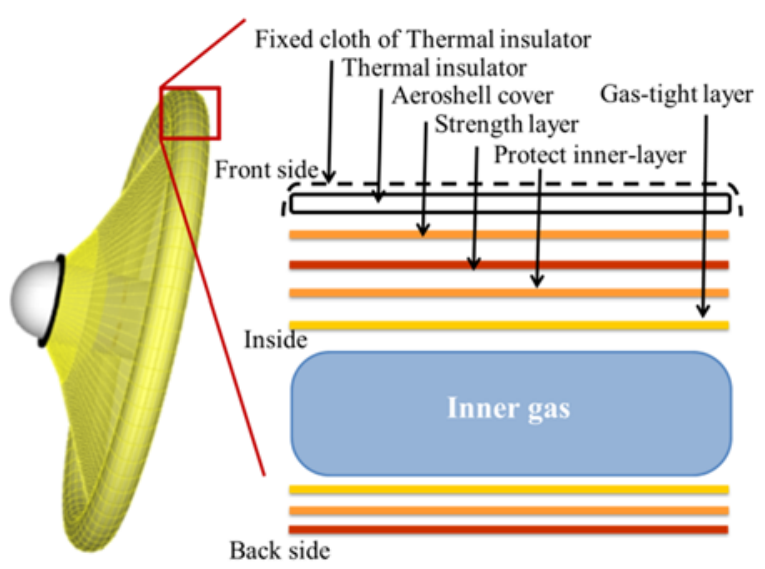

Fig. 3. Schematic sketch of layering structure of inflatable ring.

Table 2. Materials for inflatable ring of membrane aeroshell for reentry vehicle.

\begin{tabular}{ll}
\hline Structure & material \\
\hline Gas-tight layer & $\begin{array}{l}\text { Polyimide film }(12.5 \mu \mathrm{m}) \\
\text { Flameproof silicon bond }\end{array}$ \\
\hline Protect inner-layer & ZYLON filament textile \\
\hline Strength layer & ZYLON filament textile $\times 2$ \\
\hline Aeroshell cover & ZYLON filament textile \\
\hline Thermal insulate layer & Almina continuous fiber felt \\
\hline Thermal insulate cover & Almina continuous fiber cloth \\
\hline
\end{tabular}

\section{Test Facility}

The heating tests were carried out using the inductively coupled plasma (ICP) heater with a maximum input power of 
$10 \mathrm{~kW}$, which is located in ISAS. This facility can produce a plasma flow with high enthalpy and relatively low heat flux because the ICP torch generally can ignite plasma under a low ambient density condition. This condition is close to the aerodynamic heating condition of the low ballistic coefficient atmospheric entry vehicle with the membrane aeroshell. Therefore, the ICP heater is suitable to evaluate the inflatable structure for the atmospheric entry vehicle. This facility produces continuous plasma flow with a relatively low heat flux from $100 \mathrm{~kW} / \mathrm{m}^{2}$ to $400 \mathrm{~kW} / \mathrm{m}^{2}$. The ICP heater can simulate the aerodynamic heating condition of the assumed atmospheric entry with a membrane aeroshell. Figure 4 shows the appearance of this ICP heater. The ICP heater is composed of four subsystems: (1) Main unit. (2) Vacuum chamber and vacuum exhaust device. (3) Gas supply system. (4) Cooling system. The main unit is composed of the plasma torch, high-frequency power supply, and matching box.

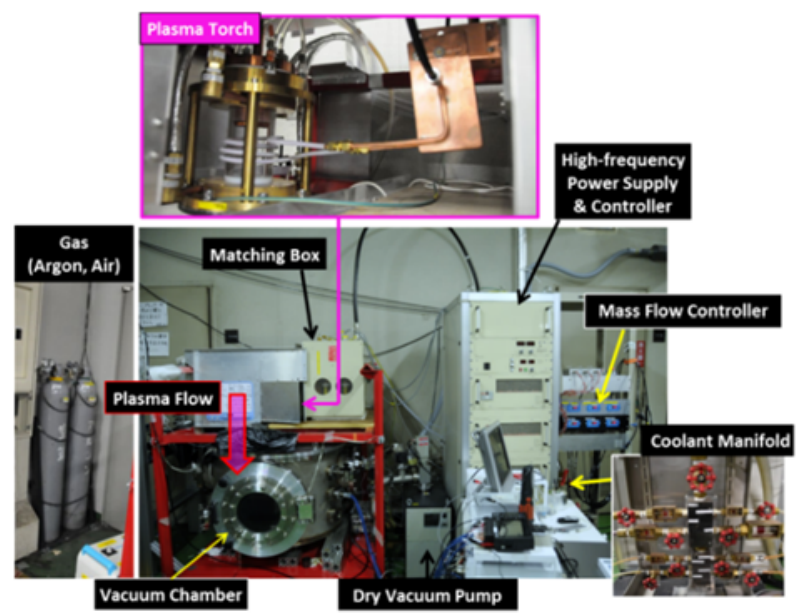

Fig. 4. Appearance of the $10 \mathrm{~kW}$ ICP heater located in ISAS.

The main unit of the ICP heater was designed and manufactured by Nihon Koshuha Co., Ltd. based on the 110 kW ICP-heated wind tunnel in JAXA Chofu Aerospace Center. ${ }^{7}$ However, the maximum input power of this facility is $10 \mathrm{~kW}$. The inner diameter of the quartz tube in the plasma torch is $75 \mathrm{~mm}$. The diameter of the core flow using the 50 $\mathrm{mm}$ diameter orifices at exit of the torch is about $50 \mathrm{~mm}$. The specifications of the developed ICP heater are summarized in Table 3.

Table 3. Specifications of ICP heater used for the heating test.

\begin{tabular}{ll}
\hline Manufacture of Min Unit & Nihon Koshuha Co., Ltd \\
\hline Power Supply Frequency & $4 \mathrm{MHz} \pm 0.05 \%$ \\
\hline Required Power & 3-phase AC200V, 24 kVA \\
\hline Input Power Range & $0-10 \mathrm{~kW}(3 \mathrm{~kW} \times 4$ units $)$ \\
\hline Inner diameter of quartz tube & $\Phi 75 \mathrm{~mm}$ \\
\hline Diameter of Coil & $\Phi 96 \mathrm{~mm}$ \\
\hline Coil turns & 3 turns \\
\hline Required coolant flow rate & $62 \mathrm{~L} / \mathrm{min}$ \\
\hline Mass flow controller & Kofloc MODEL8500 \\
\hline Motor-operated Valve & CKD EVB517 \\
\hline Diameter of Orifice & $50 \mathrm{~mm}$ \\
\hline
\end{tabular}

There are three routes for the driving gas supply to the plasma torch, named as A-gas, B-gas, and C-gas. A-gas flows into the center of the torch in the axial direction. B-gas flows from the periphery to the center, in a radial direction. C-gas flows from the periphery, in a helical direction. After the driving gas becomes plasma at the torch, it flows downward to the vacuum chamber. A dry vacuum pump is connected to the chamber via a motor-operated valve. The chamber pressure is roughly controlled by regulating the aperture ratio of the motor-operated valve in 32 steps.

\section{Test Model}

\subsection{Basic structure}

The test models used in the heating tests are simple cylindrical inflatable structures. Figure 5 is a photograph of the test model with its basic structure. This model has a diameter of $50 \mathrm{~mm}$ and a length of about $210 \mathrm{~mm}$. Its basic design concept is the same as that described in Fig. 2 and Table 1. This inflatable structure consists of three-layers. The inner gas is sealed by the gas-tight inner layer made of polyimide film with thickness of $12.5 \mu \mathrm{m}$. The middle layer is a protection layer, made of a ZYLON filament textile. The outer layer is the strength layer, which is composed of two overlapped ZYLON filament textiles, with its direction shifted by $45^{\circ}$ from each other to withstand the tensile stress owing to the inner pressure.

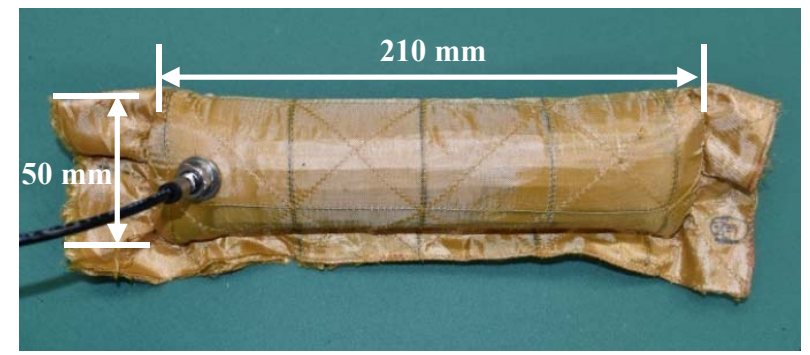

Fig. 5. The basic structure of inflatable model used for heating test made of ZYLON textile, polyimide film and silicon rubber adhesive.

\subsection{Black thermal insulating layer}

The basic structure explained in the previous section is covered by a thermal insulating layer, which is composed of two black alumina continuous fiber felts with thickness of 6 $\mathrm{mm}$, to improve the thermal durability. In addition, the alumina felts are covered and fixed by a double alumina continuous fiber cloth. This thermal insulating layer and its cover are attached only on the front heated surface in an actual mission. The heat input on the heated surface is determined according to the balance between the aerodynamic heating and radiation cooling. From the back surface of the inflatable torus, heat is dissipated by radiation cooling. However, not only the front surface but also the back one are heated by the plasma flow in the heating test using the ICP heater. This occurs because the plasma flow produced by the ICP heater is a subsonic flow.

This fact causes a severe discrepancy from the actual aerodynamic heating environment. Therefore, the test model is covered by a black thermal insulator layer not only on the 
front surface but also on the back side, as shown in Fig. 6. This is the final assembly of the test model for the heating test. Both ends of the model are covered by white alumina felt and metal caps to prevent heat input from the edge of the model.

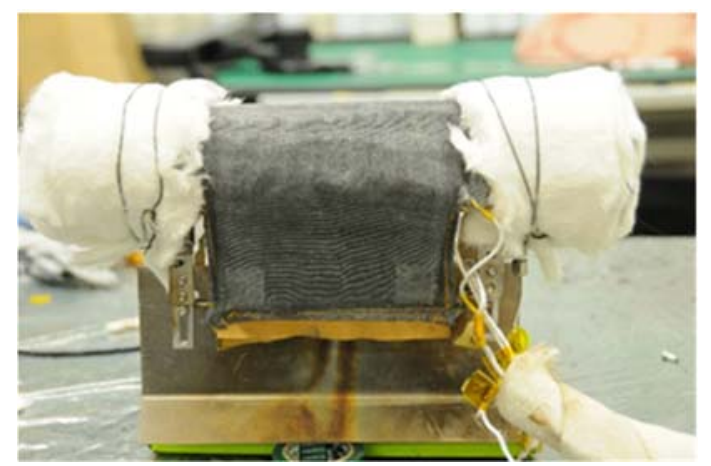

Fig. 6. Final assembly of the inflatable test model covered by a black thermal insulator.

\section{Test Method and Measurement Items}

The gas flow rate and the input power of the ICP heater are adjusted to produce a stable plasma flow with a heat flux of $110 \mathrm{kw} / \mathrm{m}^{2}$, which is equal to the maximum heat flux of the aerodynamic heating environment of the membrane aeroshell. The inner pressure in the inflatable model is set to about 120 $\mathrm{kPa}$ absolute before the tests. In these tests, the heating duration is $300 \mathrm{~s}$. The temperatures on the front surface of the strength layer and on its backside are measured by thermocouples embedded in the inflatable model. The time history of the inner pressure inside the inflatable model is measured to monitor whether the gas-tight condition is maintained or broken. The heat flux of the plasma flow was measured by Gurdon-type heat flux sensors in $10 \mathrm{~s}$, before and after the injection of the inflatable model.

In addition to the case with double thermal insulating layers, models with single and triple thermal insulating layers were tested to investigate the effects of thermal insulator thickness on thermal durability. The heating test was carried out four times for each model.

\subsection{Heat flux measurement}

Table 4 is the catalog specification of the heat flux sensor used in this test. This sensor is attached on a cylindrical anchorage made of copper, which has the same configuration as the simple cylindrical inflatable models. Figure 7 is a photograph of the heat flux sensor and anchorage.

Table 4. Specifications of the Heat flux sensor.

\begin{tabular}{ll}
\hline Basis & Gurdon type \\
\hline Manufacture & MEDTHERM \\
\hline Model & GTW-100-8-36-40-484 \\
\hline Maximum heat flux & $1000 \mathrm{~kW} / \mathrm{m}^{2}$ \\
\hline \multirow{2}{*}{ Configuration } & $\begin{array}{l}\text { Diameter } 15.6 \mathrm{~mm} \\
\text { High } 25.5 \mathrm{~mm}\end{array}$ \\
\hline Sensitivity coefficient & $86.43 \mathrm{~kW}\left(\mathrm{~m}^{2}, \mathrm{mV}\right)$ \\
\hline
\end{tabular}

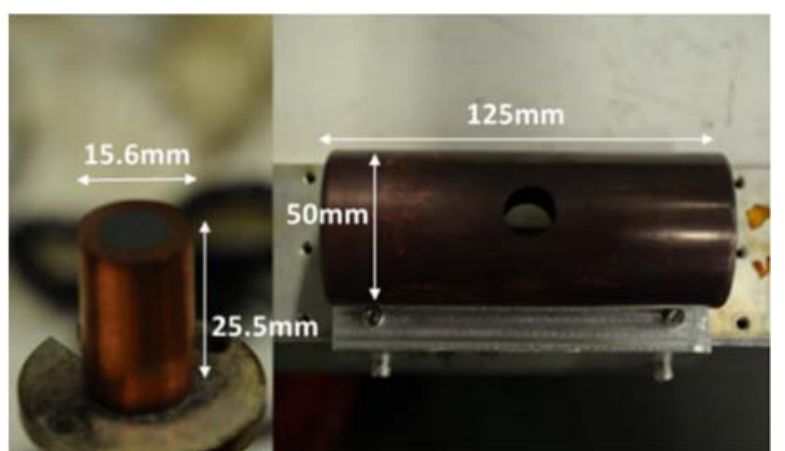

Fig. 7. Gurdon-type heat flux sensor used in this test (left) and cylindrical anchorage made of copper (right).

\subsection{Temperature measurement in test model}

Temperature of the test model is measured by K-type thermocouples. The measurement points are shown in Fig. 8. One is at the surface of the strength layer of the front surface. Another is on the backside of the strength layer, near the bonding line, made of silicon rubber adhesive, of the gas-tight layer.

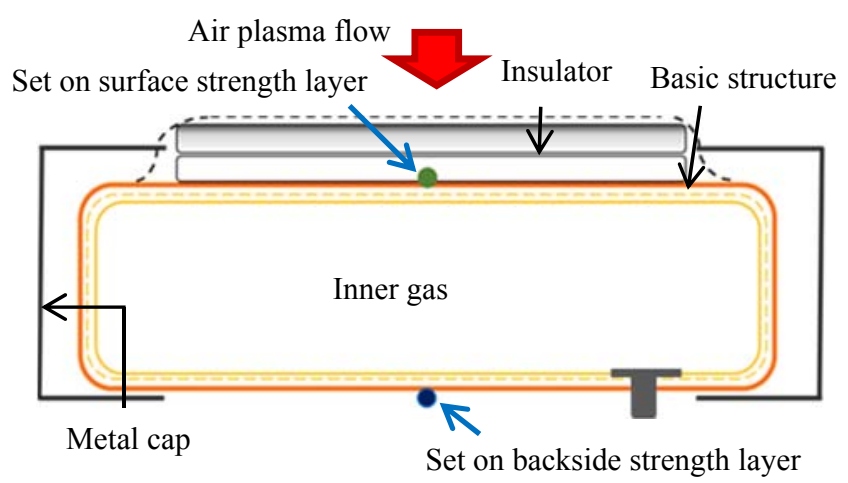

Fig. 8. Position of the thermocouples to measure the temperature history on the inflatable model.

\section{Test Results}

An inflatable structure model exposed to the air plasma flow produced by the ICP heater is shown in Fig. 9. The center of the inflatable model was heated by the air plasma flow. The heated surface becomes red owing to the high temperature, which may reach $1000{ }^{\circ} \mathrm{C}$. Twelve tests were carried out, changing the thickness of the thermal insulator as a parameter. The double-layer thermal insulating layer with a thickness of $12 \mathrm{~mm}$ is defined as the standard case. In addition, a single layer with a thickness of $6 \mathrm{~mm}$, and a triple-layer, with a thickness of $18 \mathrm{~mm}$, were also tested. These four tests were carried out for each model, and a new model was used for each test. The temperature in the inflatable structure model and the inner pressure were measured in all the cases. 


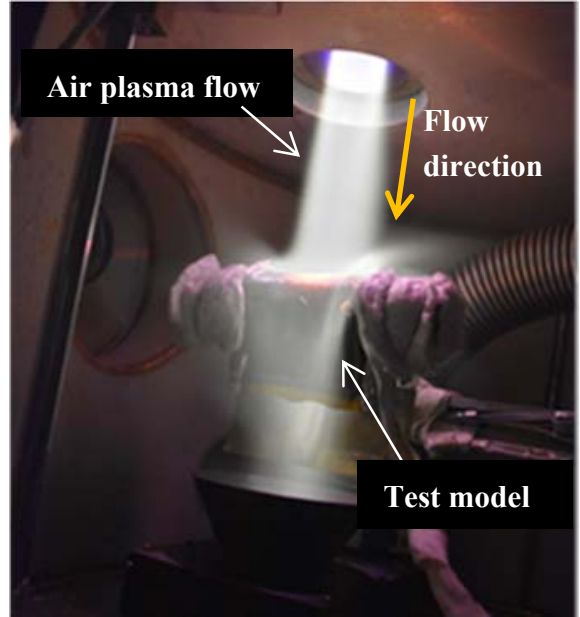

Fig. 9. Inflatable structure model exposed to air plasma produced by ICP heater.

\subsection{Heat flux of air plasma flow}

The heat flux was measured using a Gurdon-type heat flux sensor as described in the previous section, $10 \mathrm{~s}$ before and after exposing the inflatable model to the air plasma flow, to check the flow condition in every case. Table 5 shows the results of the time averaged heat flux. The target value of the heat flux in this test was $110 \mathrm{~kW} / \mathrm{m}^{2}$, according to an estimation of the aerodynamic heating environment. As listed in Table 5 , the heat flux is in the range of $104.4 \mathrm{~kW} / \mathrm{m}^{2}$ to $115.7 \mathrm{~kW} / \mathrm{m}^{2}$, and the difference from the target value is less than $5 \%$. Further, the variation of the heat flux is $20 \mathrm{~kW} / \mathrm{m}^{2}$ in each case of the same model. This is acceptable because this variation does not have a critical impact on the temperature histories in the inflatable model.

Table 5. Time-averaged heat flux measured by Gurdon-type heat flux sensor before and after heating test in every case.

\begin{tabular}{lcccccc}
\hline $\begin{array}{c}\text { Number } \\
\text { of } \\
\text { insulate }\end{array}$ & \multicolumn{2}{c}{ Single layer } & \multicolumn{2}{c}{ Double layers } & \multicolumn{2}{c}{ Triple layers } \\
\cline { 2 - 7 } & After & Before & After & Before & After \\
\hline No. 1 & 101.8 & 112.6 & 118.2 & 113.1 & 114.5 & 108.5 \\
\hline No. 2 & 122.1 & 120.7 & 120.6 & 115.7 & 105.3 & 102.3 \\
\hline No. 3 & 106.0 & 106.9 & 110.4 & 104.1 & 108.7 & 98.7 \\
\hline No. 4 & 113.9 & 114.8 & 113.5 & 109.8 & 112.9 & 107.9 \\
\hline Total ave. & 111.0 & 113.8 & 115.7 & 110.7 & 110.4 & 104.4 \\
\hline
\end{tabular}

\subsection{Effect of thickness of thermal insulating layer \\ 6.2.1. Standard double layered blackened thermal insulation}

The heating test was conducted four times on the inflatable model covered by double thermal insulating layers with a thickness of $12 \mathrm{~mm}$. The temperature histories in the heating tests are shown in Fig. 10. From these results, the temperature on the inflatable model on the heated side increased when the model was injected with plasma flow and reached about $470{ }^{\circ} \mathrm{C}$ at a maximum of $300 \mathrm{~s}$ after the injection. The temperature on the back surface became near $300{ }^{\circ} \mathrm{C}$, at the maximum. Repeatability was allowable because the temperature variation was about $30{ }^{\circ} \mathrm{C}$ in the four tests. The discontinuity in temperature change at the time of $380 \mathrm{~s}$ was caused by the electrical noise when the ICP torch was turned off. This does not affect the test results because the model was already ejected from the plasma flow.

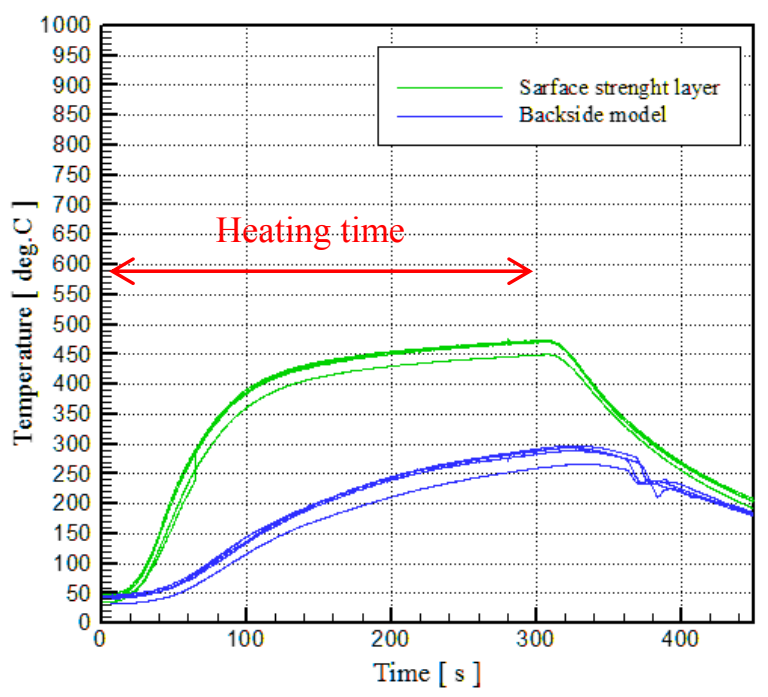

Fig. 10. Time history of the temperatures in envelop of inflatable structure covered double insulates measured in heating test.

The time history of the inner pressures is shown in Fig. 11. The pressure increase was observed up to about $200 \mathrm{kPa}$ from $120 \mathrm{kPa}$, owing to the increase in inner gas temperature. A discontinuity in the pressure history was not observed during these tests. This fact proves that the gas-tight layer is intact and can keep the inner pressure. From these results, it was confirmed that the gas-tight layer can achieve and maintain its function under an air plasma flow with a heat flux of 110 $\mathrm{kW} / \mathrm{m}^{2}$, thanks to its double blackened alumina thermal insulating layers with a thickness of $12 \mathrm{~mm}$.

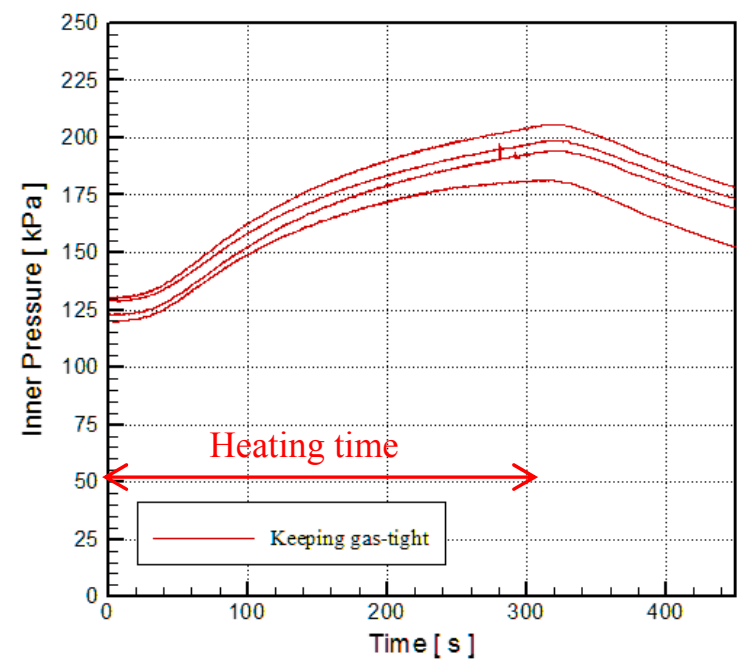

Fig. 11. Time history of inner pressures in inflatable structure covered with double insulating layer, measured in heating test.

\subsubsection{Single blackened thermal insulating layer}

The second case corresponds to the inflatable models with single thermal insulating layer, with a thickness of $6 \mathrm{~mm}$. The 
temperature history in this case is shown in Fig. 12. The temperature on the heated side increased more rapidly than in the standard case and reached about $620^{\circ} \mathrm{C}$ at a maximum of $300 \mathrm{~s}$ after the model injection. The temperature on the backside reached $400{ }^{\circ} \mathrm{C}$ at the maximum. A discontinuity in the temperature history was observed at $80 \mathrm{~s}$ in one case. Its cause may be the breakage of inflatable model.

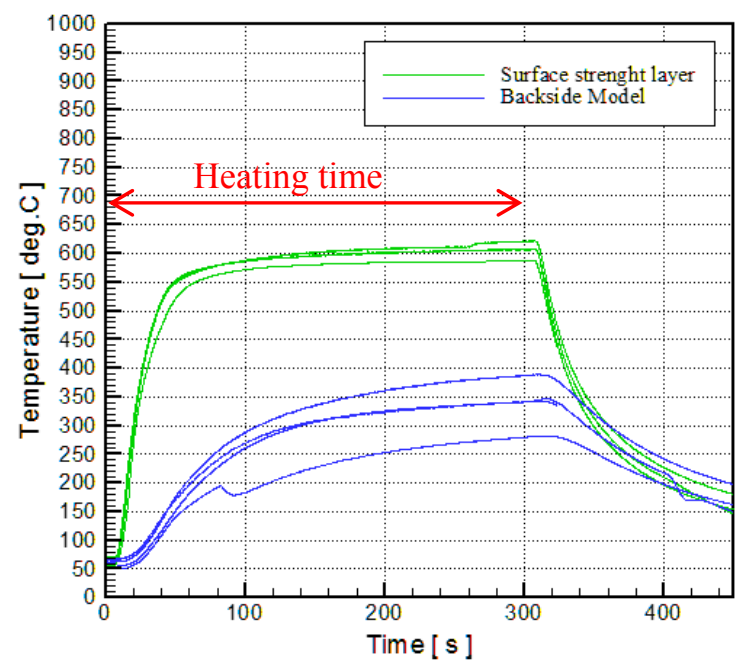

Fig. 12. Time history of temperatures in envelop of inflatable structure covered with single insulating layer in heating test.

The inner pressure history is shown in Fig. 13. The inner pressure also increased more quickly than in the standard model case because the gas temperature increased rapidly. In the two cases represented in a blue line, the pressure history changed discontinuously and decreased rapidly during heating. This result indicates that these models were broken and the inner gas leaked. The inspection of the broken models after the heating tests proved some damage of the gas tight layers of the inflatable model. This breakage caused the separation of the thermocouple and the discontinuous change in the temperature history on the backside, as shown in Fig. 12 with the blue lines.

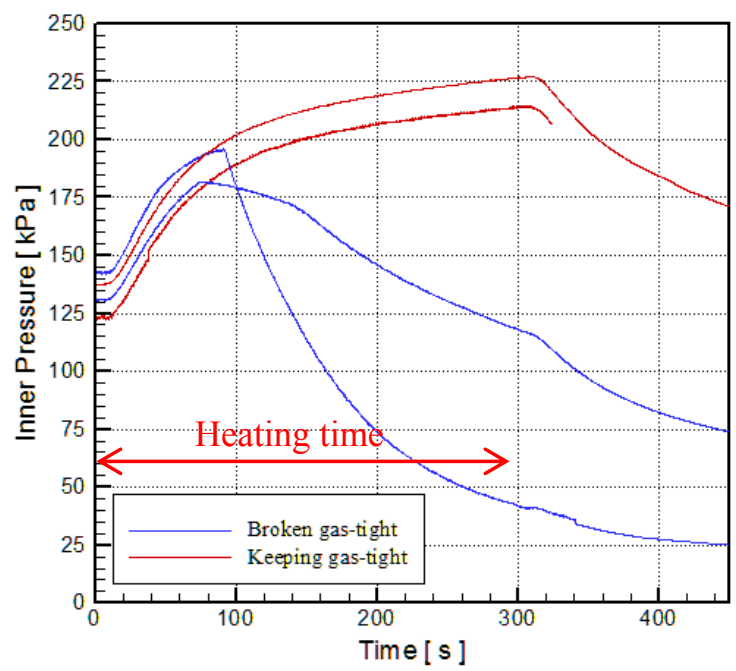

Fig. 13. Time history of the inner pressures in envelop of inflatable structure covered with single insulating layer in heating test.
The temperature measurement point on the strength layer in the front side contacts with the polyimide film and the measurement points on backside are near the adhesive line. The maximum allowable temperatures of the polyimide film used in the gas-tight layer of the inflatable structure and silicon rubber adhesive are $550{ }^{\circ} \mathrm{C}$ and $300{ }^{\circ} \mathrm{C}$, respectively. The maximum temperature on the front and back side recorded in these tests exceeded the allowable temperatures. This is the reason why the gas-tight layer was broken during heating. Therefore, it is difficult to withstand an air plasma flow with heat flux of $110 \mathrm{~kW} / \mathrm{m}^{2}$ with a single thermal insulating layer with a thickness of $6 \mathrm{~mm}$ for $300 \mathrm{~s}$.

\subsubsection{Triple blackened thermal insulating layers}

The final case corresponds to the inflatable models with triple thermal insulating layers with a thickness of $18 \mathrm{~mm}$. The temperature history is shown in Fig. 14. The temperature on the heated side increased more slowly than in the standard case and reached about $400{ }^{\circ} \mathrm{C}$ at the maximum of $300 \mathrm{~s}$ after the model injection. The temperature on the back side reached $250{ }^{\circ} \mathrm{C}$ at the maximum.

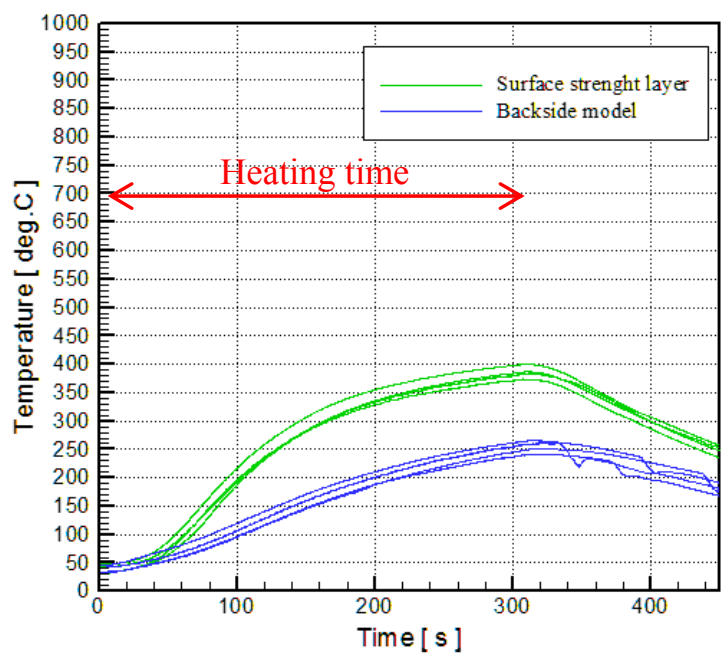

Fig. 14. Time history of the temperatures in envelop of inflatable structure covered with triple insulating layer in heating test.

The inner pressure history is shown in Fig. 15. The inner pressure increased with the same trend as in the standard case. A discontinuity in the change of inner pressure was not observed during heating, and the gas-tight condition of the inflatable models was intact in these cases.

The temperature increase rate, peak temperature, and maximum inner pressure of the models with triple thermal insulating layers are lower than in the case of the standard model thanks to the thickness of the thermal insulator, which is of $18 \mathrm{~mm}$. In this case, the peak temperature is lower than the allowable temperature of all materials used in the inflatable model, the same as in the standard models. The inflatable models with triple thermal insulating layer model can survive an air plasma flow with heat flux of $110 \mathrm{~kW} / \mathrm{m}^{2}$ without any damage of the gas-tight layer. 


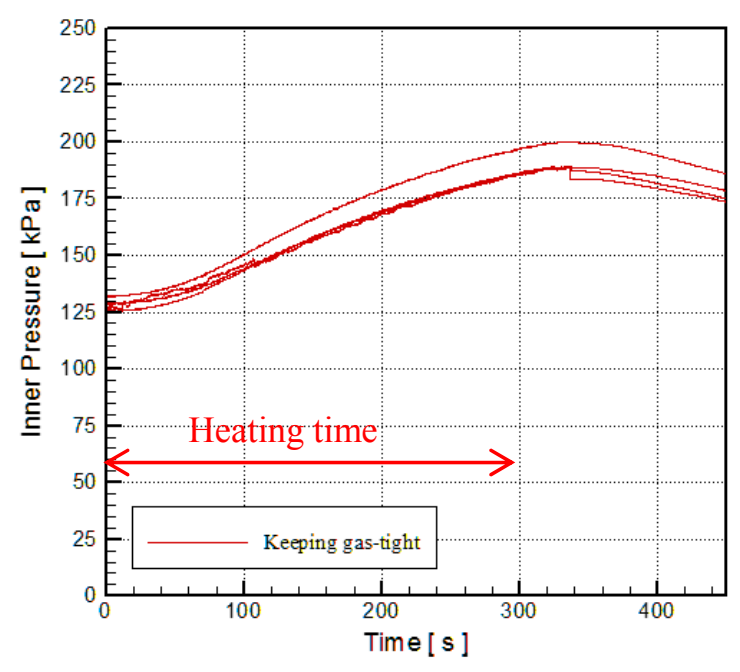

Fig. 15. Time history of the inner pressures in the envelop of inflatable structure covered with triple insulating layer in heating test.

\subsection{Summary and discussion}

Table 6 is the summary of results of the evaluation tests on the survivability of each inflatable model with varying thickness of the thermal insulator layers. Figure 16 shows the relation between the number of thermal insulate layers and the peak temperature on the strength layer, on both the front and back side. From this result, in each case, temperature decreases as the number of thermal insulating layer increases. This result indicates that the inflatable structure can survive the aerodynamic heating condition with a heat flux of 110 $\mathrm{kW} / \mathrm{m}^{2}$ if the thickness of the blackened thermal insulator made of alumina felt is over $12 \mathrm{~mm}$.

Therefore, we conclude that thermal durability performance of the inflatable structure could be quantitatively evaluated using the ICP heater and a simple cylindrical inflatable model. These results are an important first step in the research to understand the complex phenomena occurring in an inflatable structure under an aerodynamic heating environment. First, these results show that the selected flexible materials, including ZYLON filament, polyimide film, and alumina felt, function with a reasonable performance, compared with the catalog specifications, under the aerodynamic heating condition with a plasma flow. Additionally, the reasonable results and trends with respect to the effects of the thermal insulating layer made of alumina felt was confirmed in this test with sufficient experimental repeatability. These results are very useful as a reference case for the development of a numerical tool to simulate and predict the real aerodynamic entry condition.

Table 6. Summary of the evaluation test results about the survivability of each inflatable model.

\begin{tabular}{cccc}
\hline & Single layer & Double layers & Triple layers \\
\hline $\begin{array}{c}\text { Remain } \\
\text { gas-tight }\end{array}$ & 2 cases & 4 cases & 4 cases \\
\hline $\begin{array}{c}\text { Broken } \\
\text { gas-tight }\end{array}$ & 2 cases & 0 cases & 0 cases \\
\hline
\end{tabular}

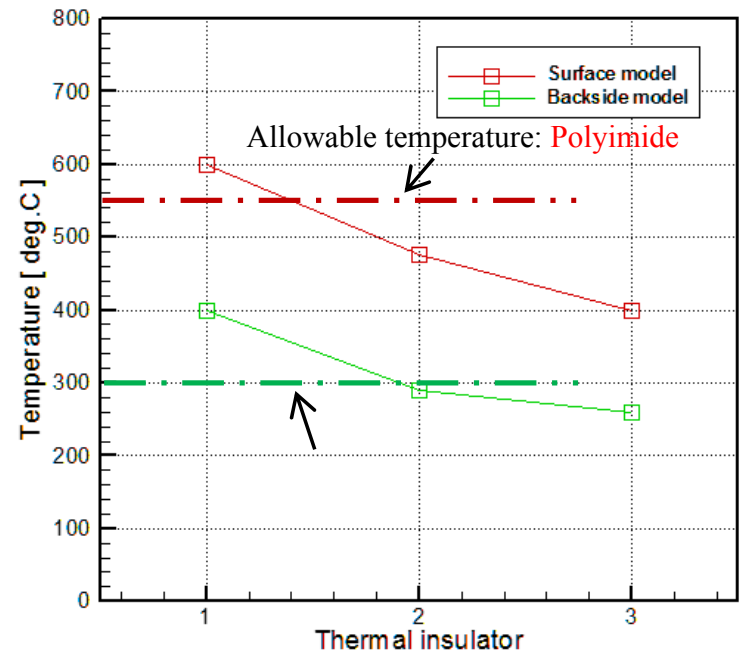

Fig. 16. The relation between the number of the thermal insulator layers and peak temperature on the front and back side measured in the heating tests.

\section{Conclusion}

Heating tests using the ICP heater were carried out to evaluate the thermal durability of the inflatable structure against aerodynamic heating. The results indicate that the inflatable structure made of polyimide film, silicon rubber adhesive, ZYLON textile, and alumina felt can survive a plasma flow with a heat flux of $110 \mathrm{~kW} / \mathrm{m}^{2}$ during $300 \mathrm{~s}$, which is an equivalent condition to the assumed atmospheric entry environment for a vehicle with a large and low-mass membrane aeroshell, if the thickness of the alumina felt thermal insulator is more than $12 \mathrm{~mm}$. The thermal durability performance of the inflatable structure could be quantitatively evaluated using the ICP heater and a simple cylindrical inflatable model, because the results are reasonable when compared with the catalog specifications.

In the future, we will elucidate the heat transfer mechanism of the inflatable structure exposed to the atmospheric entry environment based on these experimental results, with the support of numerical simulations. Furthermore, the optimal thickness of the thermal insulator for the actual reentry vehicle will be determined according to the numerical simulation and additional ground tests.

\section{References}

1) Yamada, K., Suzuki, K., Abe, T., Imamura, O., Akita, D., and MAAC research and development group: Research and Development of Deployable Membrane Aeroshell Atmospheric Entry Vehicle MAAC and Its Future Prospect, Japan Society for Aeronautical and Space Science, 59 (2011), pp. 389-395 (in Japanese).

2) Yamada, K., Suzuki, K., Abe, T., Nagata, Y., Imamura, O., Akita, D., Takahashi, Y., Honma, N., Watanabe, Y., Iino, T., Sasaki, K., and MAAC research and development group: Atmospheric-entry Flight Test of Deployable Membrane Aeroshell using S-310 Sounding Rocket, 29th International Symposium on Space Technology and Science, ISTS 2013-m-10, 2013.

3) Imamura, O., Suzuki, K., Abe, T., Akita, D., Nagata, Y., Takahashi, Y., and Yamada, K.: Deployment Progress of Re-entry Nano-Satellite with Gossamer Aeroshell and GPS/Iridium Deployed from ISS (EGG), Symposium on Space Science and 
Technology, JSASS 2015-4452, 2015 (in Japanese).

4) Tauber. M, E. and Bowles, J. V.: Use of Atmospheric Braking During Mars Missions, J. Spacecraft and Rockets, 27(1990), pp. 514-521.

5) Yamada, K., Suzuki, K., Nagata, Y., Imamura, O., Akita, D., Takahashi, Y., and MAAC research and development group: Technical Issues to Realize the Atmospheric-entry System Using Inflatable Aeroshell, 58th Symposium on Space Science and Technology, JSASS 2014-4188, 2014 (in Japanese).

6) Matsumaru, K., Yamada, K., Imamura, O., Doi, S., Kawamoto, D., and Tanaka, M.: The Heating Test of Inflatable Structure for a Flexible Aeroshell Using ICP Heater, Proceedings at The 47th Symposium on Japan Society for Aeronautical and Space Sciences, JSASS 2016-1015, 2016 (in Japanese).

7) Ito, T., Kurotaki, T., Sumi, T., Fujita, K., Ishida, K., and Mizuno, M.: Evaluation of Surface Catalytic Effect on TPS in $110 \mathrm{~kW}$ ICP-heated Wind Tunnel, AIAA Paper 2003-0723, 2003. 